\title{
Associations between metabolic syndrome and type of dementia: analysis based on the National Health Insurance Service database of Gangwon province in South Korea
}

\author{
Yeo Jin Kim ${ }^{1 \dagger}$, Sang Mi Kim ${ }^{2 \dagger}$, Dae Hyun Jeong ${ }^{3}$, Sang-Kyu Lee ${ }^{4}$, Moo-Eob Ahn ${ }^{5}$ and Ohk-Hyun Ryu ${ }^{6 *}$
}

\begin{abstract}
Background: Metabolic syndrome is a cluster of conditions that occur together, increasing the risk of cardiovascular disease. However, the relationship between metabolic syndrome and dementia has remained controversial. Using nationwide population cohort data, we investigated the association between metabolic syndrome and dementia, according to the dementia type.
\end{abstract}

Methods: We analyzed data of 84,144 individuals, in the aged group of more than 60 years, between January 1, 2009, to December 31, 2009, at Gangwon province by using the information of the (Korean) National Health Insurance Service. After eight years of gap, in 2017, we investigated the relationship between metabolic syndrome and dementia. We classified Dementia either as dementia of the Alzheimer type (AD) or vascular dementia (VD). AD and VD were defined as per the criteria of International Classification of Disease, Tenth Revision, Clinical Modification codes. Multiple logistic regression analyses examined the associations between metabolic syndrome or five metabolic syndrome components and dementia. Analyses included factors like age, sex, smoking, alcohol, physical inactivity, previous stroke, and previous cardiac disease.

Results: Metabolic syndrome was associated with $A D(O R=11.48,95 \% \mathrm{Cl} 9.03-14.59)$, not with VD. Each of five components of metabolic syndrome were also associated with $A D$. (high serum triglycerides: $\mathrm{OR}=1.87,95 \% \mathrm{Cl} 1.60-2.19$; high blood pressure: $\mathrm{OR}=1.85,95 \% \mathrm{Cl} 1.55-2.21$; high glucose: $\mathrm{OR}=1.77,95 \% \mathrm{Cl} 1.52-2.06$; abdominal obesity: $\mathrm{OR}=1.88,95 \% \mathrm{Cl} 1.57-2.25$; low serum high-density lipoprotein cholesterol: $\mathrm{OR}=1.91,95 \% \mathrm{Cl} 1.63-2.24)$ However, among components of metabolic syndrome, only the high glucose level was associated with VD. $(\mathrm{OR}=1.26,95 \% \mathrm{Cl}$ 1.01-1.56) body mass index (BMI), fasting glucose, and smoking were also associated with AD. (BMI: $O R=0.951,95 \%$ $\mathrm{Cl}$ 0.927-0.975; fasting glucose: $\mathrm{OR}=1.003,95 \% \mathrm{Cl} 1.001-1.005$; smoking: $\mathrm{OR}=1.020,95 \% \mathrm{Cl} 1.003-1.039$ ) A history of the previous stroke was associated with both $\mathrm{AD}$ and VD. (AD: $\mathrm{OR}=1.827,95 \% \mathrm{Cl} 1.263-2.644$; VD: OR 2.775, 95\% Cl 1.747-4.406)

\footnotetext{
*Correspondence: ohryu30@gmail.com

†Yeo Jin Kim and Sang Mi Kim contributed equally to this work

${ }^{6}$ Division of Endocrinology and Metabolism, Department of Internal Medicine, Hallym University-Chuncheon Sacred Heart Hospital, Hallym University College of Medicine, 77 Sakju-ro, Chuncheon, Gangwon-do 24253, Republic of Korea

Full list of author information is available at the end of the article
}

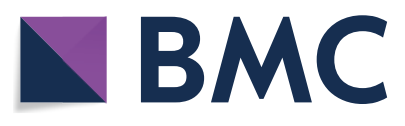

(c) The Author(s) 2021. This article is licensed under a Creative Commons Attribution 4.0 International License, which permits use, sharing, adaptation, distribution and reproduction in any medium or format, as long as you give appropriate credit to the original author(s) and the source, provide a link to the Creative Commons licence, and indicate if changes were made. The images or other third party material in this article are included in the article's Creative Commons licence, unless indicated otherwise in a credit line to the material. If material is not included in the article's Creative Commons licence and your intended use is not permitted by statutory regulation or exceeds the permitted use, you will need to obtain permission directly from the copyright holder. To view a copy of this licence, visit http://creativeco mmons.org/licenses/by/4.0/. The Creative Commons Public Domain Dedication waiver (http://creativecommons.org/publicdomain/ zero/1.0/) applies to the data made available in this article, unless otherwise stated in a credit line to the data. 
Conclusions: Metabolic syndrome was associated with AD but not with VD. Patients with metabolic syndrome had an 11.48 times more likeliness to develop AD compared to those without metabolic syndrome. VD was associated only with several risk factors that could affect the vascular state rather than a metabolic syndrome. We suggested that the associations between metabolic syndrome and dementia would vary depending on the type of dementia.

Keywords: Metabolic syndrome, National Health Insurance Service, Dementia risk, Alzheimer's disease, Vascular dementia

\section{Background}

Metabolic syndrome is a cluster of components that indicate overnutrition and includes five components that are high blood pressure (BP), high blood glucose, high serum triglycerides (TG), low serum high-density lipoprotein cholesterol (HDL-C), and abdominal obesity. Metabolic syndrome components like high blood pressure, blood glucose, abdominal obesity, and dyslipidemia are well-known factors associated with the occurrence of dementia in late life [1-4]. However, previous studies between metabolic syndrome and cognitive impairment were inconsistent. Some studies reported that metabolic syndrome was related to increased risk of cognitive impairment [5], while other studies reported no association between the two [6-8], and even some reported that metabolic syndrome decelerated cognitive impairment $[9,10]$.

Of the numerous dementia etiologies, dementia of the Alzheimer type is the most common type of dementia, about $60 \%$ of the cases [11]. Vascular dementia (VD) is the second most common type, accounting for about $20 \%$ of dementia [12]. Cardiovascular risk factors could affect the development of both types, but the extent of their influences would depend on the type of dementia. VD had a leading cause in most cases, such as ischemia, hemorrhage, anoxia, or hypoxia, while the causes of Alzheimer's disease (AD) were not well understood [12]. Yet, previous studies that investigated the relationship between dementia and metabolic syndrome usually did not consider the type of dementia.

Gangwon province is located in the northeastern part of South Korea and is divided into two areas by the Mountains. It has an aging society with a relatively low population density in Korea. Although a large part of the population resides in the urban area, 11 out of 18 administrative areas have inadequate medical facilities because of the presence of mountains. That means this area is one of the most vulnerable areas of medical service in South Korea. The risk factors related to metabolic syndrome (cardiovascular and related diseases) are not well managed in this region; therefore, the disease's characteristics might differ from other regions.

We hypothesized that metabolic syndrome would be more associated with the risk of dementia than its individual components due to the synergistic effect of vascular risk factors. We also thought that the risk of dementia associated with metabolic syndrome differed between $\mathrm{AD}$ and VD. Therefore, we analyzed the association of metabolic syndrome and its five components with the incidence of dementia (a gap of eight years), according to the dementia type, in a population-based sample in Gangwon province, South Korea.

\section{Methods}

\section{Data source and study population}

The present study was conducted using data from the South Korean National Health Insurance ServiceNational Sample Cohort (NHIS-NSC), which includes demographic information, medical use, disease information, lifestyle habits, and basic laboratory data [13, 14]. The NHIS registration is mandatory for all Koreans, and the NHIS database represents health information for almost all populations in Korea [15].

Patient data of Gangwon province in South Korea from January 1, 2009, to December 31, 2009, was included $(\mathrm{n}=455,859)$. Of these patients, we selected only those aged more than 60 years $(n=105,786)$. Patients with dementia who was diagnosed before the index day were excluded $(n=21,642)$. In the end, 84,144 individuals were included in this study. (Fig. 1) We defined diagnoses using the International Classification of Disease, Tenth Revision, Clinical Modification (ICD-10-CM) codes.

\section{Standard protocol approvals, registrations, and patient consents}

This study was approved by the Institutional Review Board of Chuncheon Sacred Heart Hospital, and all methods were performed in accordance with the approved guidelines and regulations.

\section{Definition of dementia}

For defining dementia of the Alzheimer type (AD), the code of F00 or G30 was included, but F01, F02, F03, F051, and G31 were excluded. For the definition of vascular dementia (VD), codes of F02 were included. For defining dementia of any type of dementia, the code of F00, F01, F02, F03, G30, and G31 were included. 
$\mathrm{N}=455,859$

Subjects who lived in Gangwon province from

January 1, 2009 to December 31, 2009 (index year)

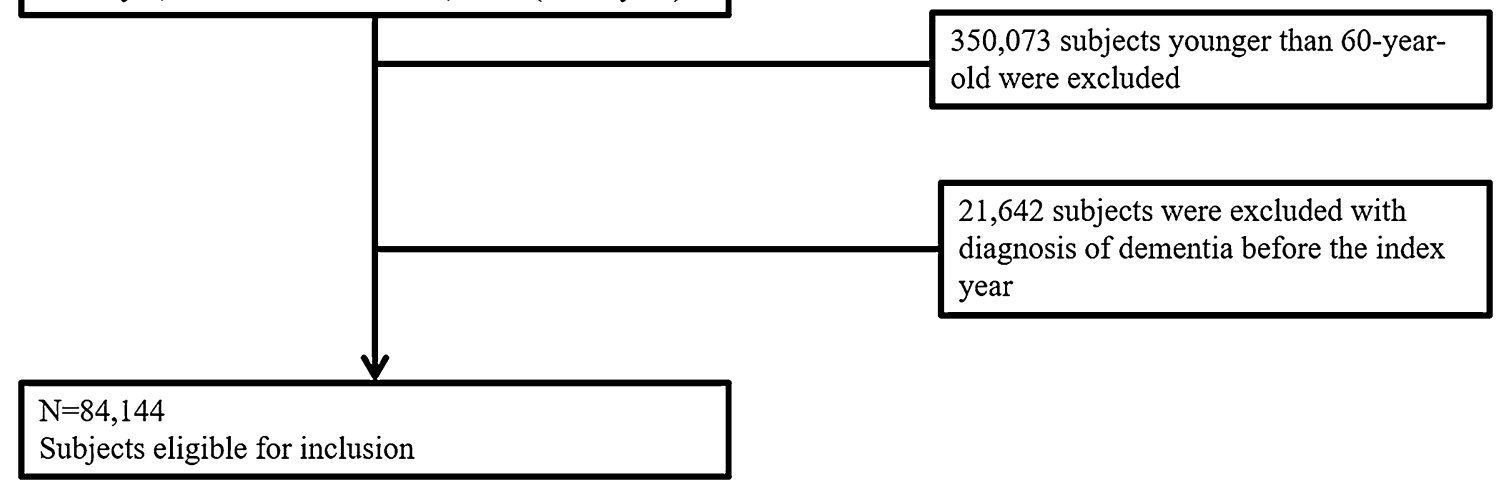

Fig. 1 Flow chart of the study population

\section{Definition of metabolic syndrome}

Individuals who met three or more of the five components were defined as having metabolic syndrome. Five components were abdominal obesity, high TG level, reduced $\mathrm{HDL}-\mathrm{C}$ level, elevated $\mathrm{BP}$, and elevated blood glucose [16]. Individuals having abdominal obesity were defined if waist circumference were over $90 \mathrm{~cm}$ in males and $80 \mathrm{~cm}$ in the female. Individuals having high TG level were defined if the serum TG level was over $150 \mathrm{mg} /$ $\mathrm{dL}$. Individuals having low HDL-C level were defined if serum HDL-C level was lower than $40 \mathrm{mg} / \mathrm{dL}$ in male and $50 \mathrm{mg} / \mathrm{dL}$ in the female. Individuals were defined as having elevated blood pressure if anti-hypertensive medications were prescribed or systolic blood pressure more than $130 \mathrm{mmHg}$ and/or diastolic blood pressure more than $85 \mathrm{mmHg}$ was recorded. Individuals having high blood glucose were defined if anti-diabetic drugs (insulins, sulfonylureas, metformin, meglitinides, thiazolidinediones, dipeptidyl peptidase- 4 inhibitors, and $\alpha$-glucosidase inhibitors) were prescribed or fasting serum glucose level was over $100 \mathrm{mg} / \mathrm{dL}$.

\section{Statistical analysis}

The baseline characteristics based on the data from the NHIS database were presented as mean values \pm standard deviation (SD) for continuous variables and percentages for categorical variables. Differences between the metabolic syndrome group and no metabolic syndrome group were confirmed using the Student t-test for continuous variables and chi-square tests for categorical variables. The relationship of metabolic syndrome and each component of metabolic syndrome for dementia was evaluated using multiple logistic regression analysis. We ran three regression models. In model 1 , we performed multiple logistic regression analyses with metabolic syndrome or each of the components as determinant and $\mathrm{AD}$ or $\mathrm{VD}$ as outcome variables after controlling for age and sex. In model 2, we performed multiple logistic regression analysis with age, sex, smoking, alcohol, physical inactivity, and metabolic syndrome. We also performed multiple logistic regression analysis with age, sex, smoking, alcohol, physical inactivity, and five metabolic syndrome components (high TG, high BP, high blood glucose, abdominal obesity, and low HDL-C). In model 3 , we performed multiple logistic regression analysis with age, sex, smoking, alcohol, physical inactivity, previous stroke, previous cardiac disease, and metabolic syndrome or five metabolic syndrome components (high TG, high BP, high glucose, abdominal obesity, and low HDL-C). Again, the relationship of other vascular risk factors for dementia was evaluated using multiple logistic regression analysis. We also ran three regression models in this analysis. In model 1, we performed multiple logistic regression analyses with vascular risk factors as determinants and $\mathrm{AD}$ or $\mathrm{VD}$ as outcome variables after controlling for age and sex. In model 2, we performed multiple logistic regression analysis with age, sex, metabolic syndrome, $\mathrm{BMI}$, systolic BP, diastolic BP, fasting glucose, and total cholesterol. In model 3, we performed multiple logistic regression analysis with age, sex, metabolic syndrome, BMI, systolic BP, diastolic BP, fasting glucose, total cholesterol, smoking, alcohol, physical inactivity, previous stroke, and previous cardiac disease. Disease risks were expressed as the odds ratio (OR) with a 95\% confidence interval (95\% CI). We defined statistical significance as $\mathrm{p}<0.05$. Statistical analyses were conducted with SPSS version 25 software (SPSS Inc., Chicago, IL, USA). 


\section{Results}

\section{Demographics and baseline characteristics}

Detailed demographic and clinical characteristics of the participants were presented in Table $1.40 .2 \%$ of participants had metabolic syndrome. The mean age of the metabolic syndrome group was higher than the no metabolic syndrome group. The metabolic syndrome group had a higher proportion of females than the no metabolic syndrome group. The no metabolic syndrome group had a higher level of physical inactivity; however, they were also engaged in smoking and alcohol intake. The mortality rate of both groups was similar.

After eight years, of the 33,828 patients with metabolic syndrome, 1380 patients (4.08\%) converted to AD, and 335 patients $(0.99 \%)$ converted to VD. Of the 50,316 patients without metabolic syndrome, 176 patients $(0.35 \%)$ converted to $\mathrm{AD}$, and 380 patients $(0.76 \%)$ converted to VD.

\section{Association between metabolic syndrome and AD}

Table 2 showed the risk of AD according to the metabolic syndrome and component of the definition of metabolic syndrome.
Metabolic syndrome was associated with AD. (OR $11.48,95 \%$ CI 9.03, 14.59, $\mathrm{p}<0.0001)$. Each of the five components of metabolic syndrome were also associated with AD. Patients with high TG had 1.87-fold odds of AD (OR 1.87, 95\% CI 1.60, 2.19, p <0.001). Patients with high BP had 1.85-fold odds of AD (OR 1.85, 95\% CI 1.55, 2.21, $\mathrm{p}<0.0001)$. Patients with high glucose levels had 1.77-fold odds of AD (OR 1.77, 95\% CI $1.52,2.06, \mathrm{p}<0.0001)$. Patients with abdominal obesity had 1.88-fold odds of AD (OR 1.88, 95\% CI 1.57, 2.25, $\mathrm{p}<0.0001$ ). Patients with low HDL-C had 1.91-fold odds of AD (OR 1.91, 95\% CI 1.63, 2.24, $\mathrm{p}<0.0001)$.

\section{Association between metabolic syndrome and VD}

Table 3 showed the risk of VD according to the metabolic syndrome and component of the definition of metabolic syndrome.

Metabolic syndrome was not associated with VD (OR 1.17, 95\% CI 0.94, 1.47, $\mathrm{p}=0.158$ ). Among the five components of metabolic syndrome, high glucose was associated with VD. Patients with high glucose had 1.26-fold odds of VD (OR 1.26, 95\% CI 1.01, 1.56,

Table 1 Demographics and baseline characteristics

\begin{tabular}{|c|c|c|c|}
\hline & Metabolic syndrome $(n=33,828)$ & No metabolic syndrome $(n=50,316)$ & $\mathrm{p}$ value \\
\hline Mean age & $67.42 \pm 5.28$ & $66.79 \pm 5.11$ & $<0.0001$ \\
\hline Sex, female number (\%) ${ }^{a}$ & $23,020(68.1)$ & $25,088(49.9)$ & $<0.0001$ \\
\hline BMl & $25.88 \pm 2.96$ & $23.68 \pm 2.90$ & $<0.0001$ \\
\hline Systolic BP & $136.61 \pm 15.15$ & $126.54 \pm 15.91$ & $<0.0001$ \\
\hline Diastolic BP & $82.03 \pm 10.12$ & $77.18 \pm 9.97$ & $<0.0001$ \\
\hline Fasting glucose & $112.14 \pm 31.27$ & $96.70 \pm 20.45$ & 0.001 \\
\hline Total cholesterol & $200.80 \pm 46.30$ & $194.55 \pm 38.46$ & $<0.0001$ \\
\hline Smoking, pack-year & $1.33 \pm 4.89$ & $2.16 \pm 5.99$ & $<0.0001$ \\
\hline Alcohol, cup/week & $1.20 \pm 2.94$ & $1.54 \pm 3.20$ & $<0.0001$ \\
\hline Previous stroke $(\%)^{\mathrm{a}}$ & $804(2.38)$ & $876(1.74)$ & $<0.0001$ \\
\hline Previous cardiac disease (\%) ${ }^{a}$ & $2137(62.2)$ & $2513(5.8)$ & $<0.0001$ \\
\hline Previous HTN (\%) & $18,062(62.2)$ & 17,180 (39.6) & $<0.0001$ \\
\hline Previous DM $(\%)^{\mathrm{a}}$ & $6969(24.1)$ & $4102(9.5)$ & $<0.0001$ \\
\hline Previous dyslipidemia (\%) & $2225(7.7)$ & $2493(5.8)$ & $<0.0001$ \\
\hline Physical inactivity (\%) & $5487(29.8)$ & $9483(35.0)$ & $<0.0001$ \\
\hline High TG $(\%)^{\mathrm{a}}$ & $21,746(64.3)$ & $7617(15.1)$ & $<0.0001$ \\
\hline High BP (\%) & $27,571(81.5)$ & $22,848(45.4)$ & $<0.0001$ \\
\hline High glucose (\%) & $22,422(33.7)$ & $12,804(74.6)$ & $<0.0001$ \\
\hline Abdominal obesity (\%) & $26,806(79.2)$ & $14,939(29.7)$ & $<0.0001$ \\
\hline Low HDL-C (\%) & $19,768(58.4)$ & $8,377(16.65)$ & $<0.0001$ \\
\hline
\end{tabular}

Data are mean $\pm S D$ unless otherwise indicated

$B M I$ body mass index, $S D$ standard deviation, $H T N$ hypertension, DM diabetes mellitus, $T G$ triglyceride, $B P$ blood pressure, $H D L-C$ high-density lipoprotein cholesterol

a Number (\%) 
Table 2 Metabolic syndrome and odds of dementia in Alzheimer's type

\begin{tabular}{|c|c|c|c|c|c|c|}
\hline & \multicolumn{2}{|l|}{ Model 1} & \multicolumn{2}{|l|}{ Model 2} & \multicolumn{2}{|l|}{ Model 3} \\
\hline & OR $(95 \% \mathrm{Cl})$ & p value & OR $(95 \% \mathrm{Cl})$ & $p$ value & OR $(95 \% \mathrm{Cl})$ & $p$ value \\
\hline MetS & $10.58(9.02,12.41)$ & $<0.0001$ & $12.03(9.58,15.10)$ & $<0.0001$ & $11.48(9.03,14.59)$ & $<0.0001$ \\
\hline Hight TG & $2.64(2.38,2.92)$ & $<0.0001$ & $2.00(1.73,2.31)$ & $<0.0001$ & $1.87(1.60,2.19)$ & $<0.0001$ \\
\hline High BP & $1.87(1.67,2.11)$ & $<0.0001$ & $1.78(1.51,2.10)$ & $<0.0001$ & $1.85(1.55,2.21)$ & $<0.0001$ \\
\hline High glucose & $2.31(2.08,2.54)$ & $<0.0001$ & $1.84(1.60,2.12)$ & $<0.0001$ & $1.77(1.52,2.06)$ & $<0.0001$ \\
\hline Abdominal obesity & $2.37(2.10,2.67)$ & $<0.0001$ & $1.77(1.50,2.09)$ & $<0.0001$ & $1.88(1.57,2.25)$ & $<0.0001$ \\
\hline Low HDL-C & $2.33(2.10,2.59)$ & $<0.0001$ & $1.95(1.69,2.26)$ & $<0.0001$ & $1.91(1.63,2.24)$ & $<0.0001$ \\
\hline
\end{tabular}

Model 1: separate models associated each exposure variable with AD with adjustment for age and sex

Model 2: single model including age, sex, smoking, alcohol, physical inactivity, and metabolic syndrome or 5 metabolic syndrome components (high TG, high BP, high glucose, abdominal obesity, low HDL-C)

Model 3: single model including age, sex, smoking, alcohol, physical inactivity, previous stroke, previous cardiac disease, and metabolic syndrome or 5 metabolic syndrome components (high TG, high BP, high glucose, abdominal obesity, low HDL-C)

$O R$ odds ratio, $C l$ confidence interval, MetS metabolic syndrome, $T G$ triglyceride, $B P$ blood pressure, $H D L-C$ high-density lipoprotein cholesterol

Table 3 Metabolic syndrome and odds of vascular dementia

\begin{tabular}{|c|c|c|c|c|c|c|}
\hline & \multicolumn{2}{|l|}{ Model 1} & \multicolumn{2}{|l|}{ Model 2} & \multicolumn{2}{|l|}{ Model 3} \\
\hline & OR $(95 \% \mathrm{Cl})$ & $p$ value & OR $(95 \% \mathrm{Cl})$ & $p$ value & OR $(95 \% \mathrm{Cl})$ & p value \\
\hline MetS & $1.08(1.02,1.15)$ & 0.006 & $1.17(0.95,1.45)$ & 0.144 & $1.17(0.94,1.47)$ & 0.158 \\
\hline Hight TG & $1.03(0.88,1.20)$ & 0.709 & $0.95(0.76,1.19)$ & 0.631 & $0.90(0.71,1.14)$ & 0.392 \\
\hline High BP & $1.07(0.92,1.25)$ & 0.404 & $1.31(1.05,1.64)$ & 0.019 & $1.25(0.99,1.58)$ & 0.066 \\
\hline High glucose & $1.30(1.11,1.50)$ & 0.001 & $1.29(1.04,1.59)$ & 0.019 & $1.26(1.01,1.56)$ & 0.042 \\
\hline Abdominal obesity & $1.08(0.92,1.21)$ & 0.362 & $0.97(0.77,1.21)$ & 0.754 & $0.99(0.78,1.26)$ & 0.939 \\
\hline Low HDL-C & $1.03(0.88,1.20)$ & 0.736 & $0.97(0.77,1.22)$ & 0.806 & $0.97(0.76,1.23)$ & 0.785 \\
\hline
\end{tabular}

Model 1: separate models associated each exposure variable with VD with adjustment for age and sex

Model 2: single model including age, sex, smoking, alcohol, physical inactivity, and metabolic syndrome or 5 metabolic syndrome components (high TG, high BP, high glucose, abdominal obesity, low HDL-C)

Model 3: single model including age, sex, smoking, alcohol, physical inactivity, previous stroke, previous cardiac disease, and metabolic syndrome or 5 metabolic syndrome components (high TG, high BP, high glucose, abdominal obesity, low HDL-C)

$O R$ odds ratio, $C l$ confidence interval, MetS metabolic syndrome, $T G$ triglyceride, $B P$ blood pressure, $H D L-C$ high-density lipoprotein cholesterol

$\mathrm{p}=0.042$ ). High $\mathrm{TG}$, high $\mathrm{BP}$, abdominal obesity, and low HDL-C were not associated with VD.

\section{Association between metabolic syndrome and Any type of dementia}

Table 4 showed the risk of any type of dementia according to the metabolic syndrome and component of the definition of metabolic syndrome.

Metabolic syndrome was associated with any type of dementia (OR 1.47, 95\% CI 1.37, 1.57, p < 0.0001). Among the five components of metabolic syndrome, high TG, high glucose, abdominal obesity, and low HDL-C were associated with any type of dementia. Patients with high TG had 1.16-fold odds of any type of dementia (OR 1.16, 95\% CI 1.08, 1.24, p <0.0001). Patients with high glucose had 1.13-fold odds of any type of dementia (OR 1.13, 95\% CI 1.05, 1.20, p < 0.0001). Patients with abdominal obesity had 1.17-fold odds of any type of dementia (OR 1.17, 95\% CI $1.09,1.26,0<0.0001)$. Patients with low HDL-C had 1.10 -fold odds of any type of dementia (OR 1.10, 95\% CI $1.03,1.18, \mathrm{p}=0.007)$.

\section{Association between other cardiovascular risk factors} included continuous metabolic parameters and dementia BMI, fasting glucose, smoking, and previous stroke history were found associated with AD (Table 5). Patients with each 1-unit $\mathrm{kg} / \mathrm{m}^{2}$ higher BMI had 0.951-fold odds of AD. (OR 0.951, 95\% CI 0.927, 0.975, p<0.0001) Patients with each 1-unit $\mathrm{mg} / \mathrm{dL}$ higher fasting glucose had 1.003-fold odds of AD. (OR 1.003, 95\% CI 1.001, 1.005, p=0.003) Patients with each 1-year higher pack/year smoking had 1.020-fold odds of AD (OR 1.020, 95\% CI 1.003, 1.039, p=0.024). Patients with having previous stroke history had 1.827-fold odds of AD. (OR 1.827, 95\% CI 1.263, 2.644, p=0.001). 
Table 4 Metabolic syndrome and odds of any type of dementia

\begin{tabular}{|c|c|c|c|c|c|c|}
\hline & \multicolumn{2}{|l|}{ Model 1} & \multicolumn{2}{|l|}{ Model 2} & \multicolumn{2}{|l|}{ Model 3} \\
\hline & OR $(95 \% \mathrm{Cl})$ & $p$ value & OR $(95 \% \mathrm{Cl})$ & $p$ value & OR $(95 \% \mathrm{Cl})$ & p value \\
\hline MetS & $1.44(1.37,1.50)$ & $<0.0001$ & $1.47(1.39,1.57)$ & $<0.0001$ & $1.47(1.37,1.57)$ & $<0.0001$ \\
\hline Hight TG & $1.25(1.20,1.31)$ & $<0.0001$ & $1.19(1.12,1.27)$ & $<0.0001$ & $1.16(1.08,1.24)$ & $<0.0001$ \\
\hline High BP & $1.04(1.00,1.09)$ & 0.073 & $1.04(0.97,1.10)$ & 0.264 & $1.06(0.99,1.14)$ & 0.092 \\
\hline High glucose & $1.19(1.14,1.24)$ & $<0.0001$ & $1.12(1.06,1.20)$ & $<0.0001$ & $1.13(1.05,1.20)$ & $<0.0001$ \\
\hline Abdominal obesity & $1.22(1.16,1.28)$ & $<0.0001$ & $1.17(1.09,1.24)$ & $<0.0001$ & $1.17(1.09,1.26)$ & $<0.0001$ \\
\hline Low HDL-C & $1.18(1.12,1.23)$ & $<0.0001$ & $1.12(1.05,1.19)$ & 0.001 & $1.10(1.03,1.18)$ & 0.007 \\
\hline
\end{tabular}

Model 1: separate models associated each exposure variable with any type of dementia with adjustment for age and sex

Model 2: single model including age, sex, smoking, alcohol, physical inactivity, and metabolic syndrome or 5 metabolic syndrome components (high TG, high BP, high glucose, abdominal obesity, low HDL-C)

Model 3: single model including age, sex, smoking, alcohol, physical inactivity, previous stroke, previous cardiac disease, and metabolic syndrome or 5 metabolic syndrome components (high TG, high BP, high glucose, abdominal obesity, low HDL-C)

$O R$ odds ratio, $C l$ confidence interval, MetS metabolic syndrome, $T G$ triglyceride, $B P$ blood pressure, $H D L-C$ high-density lipoprotein cholesterol

Fasting glucose and previous stroke history were associated with VD. Patients with each 1 -unit $\mathrm{mg} / \mathrm{dL}$ higher fasting glucose had 1.004-fold odds of VD (OR $1.004,95 \%$ CI 1.001, 1.008, $\mathrm{p}=0.012$ ). Patients with having previous stroke history had 2.775-fold odds of VD. (OR 2.775, 95\% CI 1.747, 4.406, p <0.0001).

\section{Discussion}

We investigated how metabolic syndrome and its components were associated with the development of dementia after eight years. Metabolic syndrome was associated with $\mathrm{AD}$, while it was not associated with VD. Rather than that, high fasting glucose and previous stroke history were associated with VD. BMI, fasting glucose, smoking, and previous stroke were also associated with AD.

The odds of metabolic syndrome were much greater than the sum of the odds of five components in AD. This might mean that the association between metabolic syndrome and $\mathrm{AD}$ was greater than the sum of the association between each component and AD. Metabolic syndrome represented a chronic state of inflammation, hyperinsulinemia, dyslipidemia, dysglycemia, vascular injury, and oxidative stress linked to AD [17]. Amyloid beta $(\mathrm{A} \beta)$ deposition initiated an immune response intended to clear the amyloid plaque [18]. However, this response also stimulated the cytokine cascade and reactive oxygen species (ROS), leading to neurodegeneration [19]. Furthermore, the inflammatory cascade altered phosphorylation of tau protein along with the oxidative injury to the neurons. The immune response induced by amyloid, in addition to the chronic inflammatory state due to metabolic syndrome, exacerbated the $\mathrm{AD}$ pathogenic process, leading to the progression of AD. [20, 21] Metabolic syndrome also induced oxidative stress and increased ROS production.
[22] The circulating lipid and glucose imbalance combined with ROS enhanced lipoperoxidation led to the dysfunction of the antioxidant system. This usually caused vascular injury and blood-brain barrier (BBB) dysfunction, affecting amyloid and tau accumulation and chronic hypoperfusion, leading to neuronal damage [17].

Previous studies that investigated the association between metabolic syndrome and dementia reported inconsistent results. Some studies showed an association between metabolic syndrome and AD [23, 24], while other studies showed no association [7, 25-27]. French Three-City cohort and Italian Longitudinal Study on the aging study showed that metabolic syndrome increased $\mathrm{VD}$ risk, not $\mathrm{AD}[26,27]$. Other studies showed no association between metabolic syndrome and dementia [7, 9, 28]. However, the associations between metabolic syndrome and cognitive impairment varied with the study population characteristics, various criteria used to define metabolic syndrome, diverse approaches used to assess cognitive function, and different follow-up periods [6, 24]. Also, meta-analyses showed inconsistent associations between metabolic syndrome and dementia. It was reported that there was no association between metabolic syndrome and incident dementia or AD. Metabolic syndrome only increased the risk of pure VD [8]. Another meta-analysis showed that metabolic syndrome increased the risk of conversion from mild cognitive impairment to all-cause dementia [29]. Another study reported that metabolic syndrome decreased the risk of $\mathrm{AD}$ [10]. The association between metabolic syndrome and dementia could vary depending on age, follow-up period, and genetic susceptibility [30]. Especially, Apolipoprotein E4 (APOE4), the strongest genetic risk factor for late onset $\mathrm{AD}$, was also associated with metabolic syndrome [31]. Apolipoprotein was a lipid carrying lipoprotein, which interacted with amyloid beta [32]. Influence of APOE4 on 


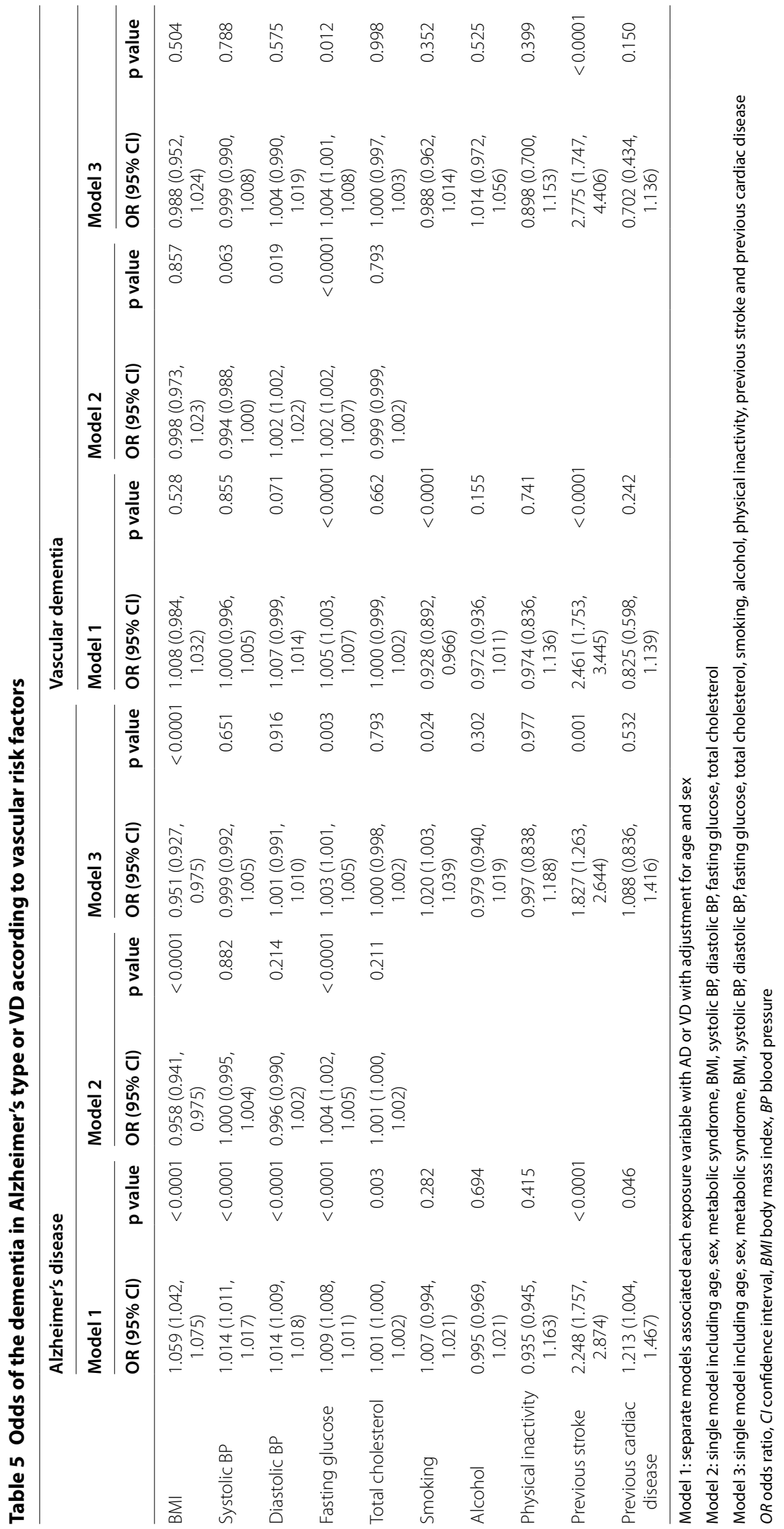


the cerebral cortex varied with age [33], and this might be related to inconsistent previous research results on the relationship between metabolic syndrome and risk of dementia.

In this study, all the five components of metabolic syndrome were associated with AD, while metabolic syndrome components except high blood glucose were not associated with VD. Although mid-life hypertension [34], mid-life dyslipidemia [35, 36], and mid-life obesity [37] were consistently related to late-life dementia, previous studies of the association between late-life vascular risk factors and dementia reported mixed results [34, 37-39]. Meanwhile, ischemia could cause up-regulation of amyloid precursor protein expression in human brains [40]. The co-existence of cerebrovascular pathology and amyloid pathology could increase clinically incident dementia [41]. Even though we removed the patients who had $\mathrm{AD}$ and $\mathrm{VD}$ code in $\mathrm{AD}$ diagnosis, it might be possible to have co-pathology in AD. AD patients who had vascular pathology could develop clinical symptoms easier than VD patients having only vascular pathology.

In this study, patients with metabolic syndrome had an 11.48 times more likeliness to develop AD compared to those without metabolic syndrome, and there was no association between metabolic syndrome and VD. In a previous study, metabolic syndrome was associated with accelerated amyloid beta accumulation in the elderly with amyloid deposition [42]. Therefore, the combination of amyloid deposition and vascular risk factors might have increased $\mathrm{AD}$ incidence in individuals with metabolic syndrome. Even taking the combination of amyloid deposition and vascular risk factor into account, this study showed a very large OR value than other studies, which might be due to racial differences. Most of the previous studies have been conducted either on the European or American populations [8]. Since this study was only on the South Korean population, one of the Asian races, there was a possibility that there might be differences in the associations between metabolic syndrome and dementia according to races.

Among components of metabolic syndrome, only high glucose level was associated with both AD and VD, while others showed association only with AD. Patients with $10 \mathrm{mg} / \mathrm{dL}$ higher fasting glucose had a $0.3 \%$ increased risk of $\mathrm{AD}$ and a $0.4 \%$ increased risk of $\mathrm{VD}$. This is consistent with previous studies showing the association between diabetes and increased risk of dementia, including all-cause dementia, AD and VD [43]. In addition, a previous study reported that, even in patients without diabetes, higher average glucose levels were associated with an increased risk of dementia [44]. Previous studies reported that diabetes mellitus not only affected cognitive decline [45] but was also associated with a high risk of cerebrovascular disease, including high white matter hyperintensities volume [46] and cerebral infarcts $[47,48]$. Impaired insulin signaling and glucose metabolism in the brain were factors that were related to $A D$ pathogenesis. Insulin modulated $A \beta$ protein precursor expression and processing [49]. Insulin not only regulated glucose and lipid metabolism in the brain but also regulated neural development and neuronal activities associated with learning and memory [50]. Insulin receptors were expressed in the brain, particularly in memory registration-related areas, such as the cerebral cortex, hippocampus, hypothalamus, and amygdala [51]. Therefore, impairment of insulin signaling led to the pathologic processes of AD. Besides, we assumed that glucose metabolism would be more closely related to the mechanism that caused cognitive impairment after the vascular event than other components. Although previous studies showed that other components of metabolic syndromes, such as hypertension [52], dyslipidemia [53], and abdominal obesity [54], also increase ischemic stroke, our study showed that these factors were not associated with VD. Another study also showed that high glucose was the most significant component associated with cognitive impairment [55].

The previous stroke was also a factor that affected both $\mathrm{AD}$ and VD. Patients having stroke history were 1.8 times more likely to develop AD and 2.8 times more likely to develop VD. The association between stroke and dementia was already reported in several studies. Ischemic stroke was a risk factor for developing AD and VD [56, 57]. Stroke doubled the risk of dementia, and approximately $20 \%$ of stroke patients went on to develop cognitive dysfunction within 3 years [58]. Ischemic stroke led to pathophysiological processes that contributed to ischemic cell damage [59]. Stimulation of the inflammatory process, free radical production, excitotoxicity, disruption of sodium and calcium influx, enzymatic changes, endothelin release, delayed coagulation, activation of platelets and leukocytes, and endothelial dysfunction were the pathophysiological reactions resulting from the onset of stroke [60]. Several studies reported a synergistic relationship between ischemic stroke and AD. Postmortem studies showed that individuals with AD pathology with cerebral infarction had a markedly increased risk of dementia than those with AD pathology without infarcts $[61,62]$. Stroke was suggested as a contributing factor to $\mathrm{AD}$ pathological changes, including selective brain atrophy and accumulation of abnormal protein such as $A \beta$ [63]. A previous study also provided evidence that stroke led to cognitive dysfunction more rapidly in patients with $\mathrm{AD}$ [64]. Besides, VD was the severest form of vascular cognitive impairment [12], and it resulted from subclinical vascular brain injury and 
stroke. Major stroke and minor stroke, and even transient ischemic attack were known to increase the risk of dementia [65].

As per our study, while patients with abdominal obesity had a higher risk of $\mathrm{AD}$, patients with higher $\mathrm{BMI}$ were less prone to $\mathrm{AD}$. This discrepancy was probably due to BMI not being a perfect indicator of obesity. BMI could not distinguish between fat and lean body mass, and because lean body mass decreased due to aging, the increase in BMI in the elderly might be due to an increase in lean body mass rather than an increase in fat [66]. On the other hand, the waist circumference used as the criterion for abdominal obesity in this study was a more accurate indicator of abdominal visceral fat level, especially in old age. [67] While adipose tissue secreted leptin, which had a good effect on brain function, [68] abdominal visceral fat increased the risk of dementia through chronic inflammation and neuronal degeneration. [69-71] Through this study, it could be assumed that abdominal visceral fat level was a more specific risk factor that increased the risk of dementia.

$\mathrm{AD}$ was also found associated with smoking. Patients with 10-year higher pack/year smoking had a $20 \%$ increased risk of AD. It was controversial whether smoking has any harmful effect on degenerative diseases. Previously some studies reported that smoking had a protective effect on degenerative diseases [72-74]. Researches even showed that nicotine had a neuroprotective and anti-aging effect $[75,76]$. However, nowadays, smoking was attributed as a risk factor for $\mathrm{AD}$ [77]. Smoking increased oxidative stress and might have indirect effects on several vascular, inflammatory, and degenerative processes $[78,79]$. If smoking particles were inhaled, they stimulated ROS production and entered the brain via blood. Smoking-related cerebral oxidative stress was a potential mechanism to accelerate $\mathrm{AD}$ pathology and increasing the risk for AD [80]. Smoking also impaired nitric oxide synthesis in cerebral vascular endothelial cells leading to interference with cerebral blood flow and glucose metabolism in the brain. [81, 82] It induced cerebral hypoperfusion and promoted the synthesis of $A \beta$ [83]. Smoking stimulated the release of proinflammatory cytokines and immune system-mediated products, causing an increase in $A \beta$ accumulation and tau phosphorylation, hallmarks of AD pathology [84].

Our study had some limitations. First, our study used claimed data, according to which we classified the types of dementia, but the actual amyloid burden was unknown. However, in order to distinguish the pure dementia type, those with codes of both $\mathrm{AD}$ and VD were excluded. Second, since we only investigated the presence of dementia eight years later, there was no consideration of what happened during the eight years and at what point dementia occurred during the eight years. Besides, there was no consideration for efforts to overcome metabolic syndrome. Some might have tried to treat metabolic syndrome, others might not, but the effect of improvement of metabolic syndrome was not known in our study. Third, there was no consideration for the duration of metabolic syndrome. The association with dementia might vary depending on how long metabolic syndrome components have existed, which were not known in our study. Therefore, further study considering the duration of metabolic syndrome is required. Finally, as the cohort only included the specific region of Korea, further investigation in other regions or population is required to generalize these findings.

Despite these limitations, we investigated the association between metabolic syndrome and different types of dementia and the association between components of metabolic syndrome and dementia, using population-based data. Therefore, we hope to provide new clinical insight into the association between metabolic syndrome and type of dementia with implications for considering different pathophysiology.

\section{Conclusions}

Metabolic syndrome was associated with $A D$, while it was not associated with VD. Patients with metabolic syndrome had an 11.48 times more likeliness to develop $\mathrm{AD}$ compared to those without metabolic syndrome. Therefore, the association between metabolic syndrome and dementia would be different depending on the type of dementia.

\section{Abbreviations}

AD: Dementia of the Alzheimer type; VD: Vascular dementia; BMI: Body mass index; BP: Blood pressure; TG: Triglycerides; HDL-C: High-density lipoprotein cholesterol; NHIS: (Korean) National Health Insurance Service; NHIS-NSC: National Health Insurance Service-National Sample Cohort; ICD-10-CM: International Classification of Disease, Tenth Revision, Clinical Modification; SD: Standard deviation; OR: Odds ratio; 95\% Cl: 95\% Confidence interval; $A \beta$ : Amyloid beta; ROS: Reactive oxygen species; BBB: Blood-brain barrier.

\section{Acknowledgements}

Not applicable.

\section{Authors' contributions}

YJK interpreted the data and drafted the manuscript. SMK contributed to the study conceptualization and the discussion of results. DHJ contributed to the study design and data analysis. SKL contributed to the data interpretation and the discussion of results. MEA contributed to the study design, data interpretation and the discussion of results. OHR contributed to the data interpretation, discussion of results and revising the manuscript. All authors read and approved the final manuscript.

\section{Funding}

This research was supported by a grant of the Korea Health Technology R\&D Project through the Korea Health Industry Development Institute 
(KHIDI), funded by the Ministry of Health \& Welfare, Republic of Korea (grant number: HI18C1623), and the National Research Foundation of Korea (NRF) grant funded by the Korean government (NRF-2017R1C1B2011637 \& NRF-2019R1H1A1035599).

\section{Availability of data and materials}

The original anonymized data used in this analysis was obtained from the NHIS of South Korea. The dataset from NHIS is not publicly available due to restricted access. However, any researcher requiring access to the data can obtain it directly through a license agreement, including the payment of appropriate license fees.

\section{Ethics approval and consent to participate}

The study was approved by the institutional review board of Chuncheon Sacred Heart Hospital.

\section{Consent for publication}

Not applicable.

\section{Competing interests}

The authors declare that they have no competing interests.

\begin{abstract}
Author details
${ }^{1}$ Department of Neurology, Hallym University-Chuncheon Sacred Heart Hospital, Hallym University College of Medicine, Chuncheon, Gangwon-do, Republic of Korea. ${ }^{2}$ Department of Big Data Analytics, Ewha Woman's University, Seoul, Republic of Korea. ${ }^{3}$ Research Institute for Gangwon, Chuncheon, Gangwon-do, Republic of Korea. ${ }^{4}$ Department of Psychiatry, Hallym University-Chuncheon Sacred Heart Hospital, Hallym University College of Medicine, Chuncheon, Gangwon-do, Republic of Korea. ${ }^{5}$ Department of Emergency Medicine, Hallym University-Chuncheon Sacred Heart Hospital, Hallym University College of Medicine, Chuncheon, Gangwon-do, Republic of Korea. ${ }^{6}$ Division of Endocrinology and Metabolism, Department of Internal Medicine, Hallym University-Chuncheon Sacred Heart Hospital, Hallym University College of Medicine, 77 Sakju-ro, Chuncheon, Gangwon-do 24253, Republic of Korea.
\end{abstract}

Received: 12 June 2020 Accepted: 21 December 2020 Published online: 06 January 2021

\section{References}

1. Ninomiya T, Ohara T, Hirakawa Y, Yoshida D, Doi Y, Hata J, et al. Midlife and late-life blood pressure and dementia in Japanese elderly: the Hisayama study. Hypertension. 2011;58(1):22-8. https://doi.org/10.1161/HYPER TENSIONAHA.110.163055.

2. Xu W, Qiu C, Gatz M, Pedersen NL, Johansson B, Fratiglioni L. Mid- and late-life diabetes in relation to the risk of dementia: a population-based twin study. Diabetes. 2009;58(1):71-7. https://doi.org/10.2337/db08-0586.

3. Luchsinger JA, Cheng D, Tang MX, Schupf N, Mayeux R. Central obesity in the elderly is related to late-onset Alzheimer disease. Alzheimer Dis Assoc Disord. 2012;26(2):101-5. https://doi.org/10.1097/WAD.0b013e318222f0d 4.

4. Xue-Shan Z, Juan P, Qi W, Zhong R, Li-Hong P, Zhi-Han T, et al. Imbalanced cholesterol metabolism in Alzheimer's disease. Clin Chim Acta. 2016:456:107-14. https://doi.org/10.1016/j.cca.2016.02.024.

5. Ho RC, Niti M, Yap KB, Kua EH, Ng TP. Metabolic syndrome and cognitive decline in chinese older adults: results from the singapore longitudinal ageing studies. Am J Geriatr Psychiatry. 2008;16(6):519-22. https://doi. org/10.1097/JGP.0b013e31816b7841.

6. van den Berg E, Biessels GJ, de Craen AJ, Gussekloo J, Westendorp RG. The metabolic syndrome is associated with decelerated cognitive decline in the oldest old. Neurology. 2007;69(10):979-85. https://doi. org/10.1212/01.wnl.0000271381.30143.75.

7. Muller M, Tang MX, Schupf N, Manly JJ, Mayeux R, Luchsinger JA. Metabolic syndrome and dementia risk in a multiethnic elderly cohort. Dement Geriatr Cogn Disord. 2007;24(3):185-92. https://doi. org/10.1159/000105927.

8. Atti AR, Valente S, lodice A, Caramella I, Ferrari B, Albert U, et al. Metabolic syndrome, mild cognitive impairment, and dementia: a meta-analysis of longitudinal studies. Am J Geriatr Psychiatry. 2019;27(6):625-37. https:// doi.org/10.1016/j.jagp.2019.01.214.

9. Forti P, Pisacane N, Rietti E, Lucicesare A, Olivelli V, Mariani E, et al. Metabolic syndrome and risk of dementia in older adults. J Am Geriatr Soc. 2010;58(3):487-92. https://doi.org/10.1111/j.1532-5415.2010.02731.x.

10. Xu W, Tan L, Wang HF, Jiang T, Tan MS, Tan L, et al. Meta-analysis of modifiable risk factors for Alzheimer's disease. J Neurol Neurosurg Psychiatry. 2015;86(12):1299-306. https://doi.org/10.1136/jnnp-2015-310548.

11. Kalaria RN, Maestre GE, Arizaga R, Friedland RP, Galasko D, Hall K, et al. Alzheimer's disease and vascular dementia in developing countries: prevalence, management, and risk factors. Lancet Neurol. 2008;7(9):81226. https://doi.org/10.1016/s1474-4422(08)70169-8.

12. Rizzi L, Rosset I, Roriz-Cruz M. Global epidemiology of dementia: Alzheimer's and vascular types. Biomed Res Int. 2014;2014:908915. https://doi. org/10.1155/2014/908915.

13. Choi JB, Lee EJ, Han KD, Hong SH, Ha US. Estimating the impact of body mass index on bladder cancer risk: Stratification by smoking status. Sci Rep. 2018;8(1):947. https://doi.org/10.1038/s41598-018-19531-7.

14. Song SO, Jung CH, Song YD, Park CY, Kwon HS, Cha BS, et al. Background and data configuration process of a nationwide population-based study using the korean national health insurance system. Diabetes Metab J. 2014;38(5):395-403. https://doi.org/10.4093/dmj.2014.38.5.395.

15. Lee SR, Choi EK, Han KD, Cha MJ, Oh S. Trends in the incidence and prevalence of atrial fibrillation and estimated thromboembolic risk using the CHA2DS2-VASC score in the entire Korean population. Int J Cardiol. 2017;236:226-31. https://doi.org/10.1016/j.ijcard.2017.02.039.

16. Alberti KG, Eckel RH, Grundy SM, Zimmet PZ, Cleeman Jl, Donato KA, et al. Harmonizing the metabolic syndrome: a joint interim statement of the International Diabetes Federation Task Force on Epidemiology and Prevention; National Heart, Lung, and Blood Institute; American Heart Association; World Heart Federation; International Atherosclerosis Society; and International Association for the Study of Obesity. Circulation. 2009;120(16):1640-5. https://doi.org/10.1161/CIRCULATIO NAHA.109.192644.

17. Luque-Contreras D, Carvajal K, Toral-Rios D, Franco-Bocanegra D, Campos-Pena V. Oxidative stress and metabolic syndrome: cause or consequence of Alzheimer's disease? Oxid Med Cell Longev. 2014;2014:497802. https://doi.org/10.1155/2014/497802.

18. Calvillo M, Diaz A, Limon DI, Mayoral MA, Chanez-Cardenas ME, Zenteno E, et al. Amyloid-beta(25-35) induces a permanent phosphorylation of HSF-1, but a transitory and inflammation-independent overexpression of Hsp-70 in C6 astrocytoma cells. Neuropeptides. 2013;47(5):339-46. https ://doi.org/10.1016/j.npep.2013.06.002.

19. Minter MR, Taylor JM, Crack PJ. The contribution of neuroinflammation to amyloid toxicity in Alzheimer's disease. J Neurochem. 2016;136(3):457-74 https://doi.org/10.1111/jnc.13411.

20. Blasko I, Stampfer-Kountchev M, Robatscher P, Veerhuis R, Eikelenboom P, Grubeck-Loebenstein B. How chronic inflammation can affect the brain and support the development of Alzheimer's disease in old age: the role of microglia and astrocytes. Aging Cell. 2004;3(4):169-76. https://doi.org/ 10.1111/j.1474-9728.2004.00101.x.

21. Milionis HJ, Florentin M, Giannopoulos S. Metabolic syndrome and Alzheimer's disease: a link to a vascular hypothesis? CNS Spectr. 2008;13(7):60613. https://doi.org/10.1017/s1092852900016886.

22. Nasoohi S, Parveen $\mathrm{K}$, Ishrat T. Metabolic syndrome, brain insulin resistance, and Alzheimer's disease: thioredoxin interacting protein (txnip) and inflammasome as core amplifiers. J Alzheimers Dis. 2018;66(3):857-85. https://doi.org/10.3233/JAD-180735.

23. Razay G, Vreugdenhil A, Wilcock G. The metabolic syndrome and Alzheimer disease. Arch Neurol. 2007;64(1):93-6. https://doi.org/10.1001/archn eur.64.1.93.

24. Vanhanen M, Koivisto K, Moilanen L, Helkala EL, Hanninen T, Soininen $\mathrm{H}$, et al. Association of metabolic syndrome with Alzheimer disease: a population-based study. Neurology. 2006;67(5):843-7. https://doi. org/10.1212/01.wnl.0000234037.91185.99.

25. Kalmijn S, Foley D, White L, Burchfiel CM, Curb JD, Petrovitch $\mathrm{H}$, et al. Metabolic cardiovascular syndrome and risk of dementia in JapaneseAmerican elderly men. The Honolulu-Asia aging study. Arterioscler Thromb Vasc Biol. 2000;20(10):2255-60. https://doi.org/10.1161/01. atv.20.10.2255. 
26. Raffaitin C, Gin H, Empana JP, Helmer C, Berr C, Tzourio C, et al. Metabolic syndrome and risk for incident Alzheimer's disease or vascular dementia: the Three-City Study. Diabetes Care. 2009;32(1):169-74. https://doi. org/10.2337/dc08-0272.

27. Solfrizzi V, Scafato E, Capurso C, D'Introno A, Colacicco AM, Frisardi V, et al Metabolic syndrome and the risk of vascular dementia: the Italian Longitudinal Study on Ageing. J Neurol Neurosurg Psychiatry. 2010;81(4):43340. https://doi.org/10.1136/jnnp.2009.181743.

28. Feinkohl I, Janke J, Hadzidiakos D, Slooter A, Winterer G, Spies C, et al. Associations of the metabolic syndrome and its components with cognitive impairment in older adults. BMC Geriatr. 2019;19(1):77. https://doi. org/10.1186/s12877-019-1073-7.

29. Cooper C, Sommerlad A, Lyketsos CG, Livingston G. Modifiable predictors of dementia in mild cognitive impairment: a systematic review and metaanalysis. Am J Psychiatry. 2015;172(4):323-34. https://doi.org/10.1176/ appi.ajp.2014.14070878

30. Bangen KJ, Armstrong NM, Au R, Gross AL. Metabolic syndrome and cognitive trajectories in the framingham offspring study. J Alzheimers Dis. 2019;71(3):931-43. https://doi.org/10.3233/JAD-190261.

31. Pendse AA, Arbones-Mainar JM, Johnson LA, Altenburg MK, Maeda N. Apolipoprotein E knock-out and knock-in mice: atherosclerosis, metabolic syndrome, and beyond. J Lipid Res. 2009;50(Suppl):S178-82. https:// doi.org/10.1194/jlr.R800070-JLR200.

32. Sanan DA, Weisgraber KH, Russell SJ, Mahley RW, Huang D, Saunders A, et al. Apolipoprotein E associates with beta amyloid peptide of Alzheimer's disease to form novel monofibrils Isoform apoE4 associates more efficiently than apoE3. J Clin Invest. 1994;94(2):860-9. https://doi. org/10.1172/JCl117407.

33. Brandon JA, Farmer BC, Williams HC, Johnson LA. APOE and Alzheimer's disease: neuroimaging of metabolic and cerebrovascular dysfunction. Front Aging Neurosci. 2018;10:180. https://doi.org/10.3389/fnagi .2018.00180.

34. van den Berg E, Kloppenborg RP, Kessels RP, Kappelle L, Biessels GJ. Type 2 diabetes mellitus, hypertension, dyslipidemia and obesity: A systematic comparison of their impact on cognition. Biochim Biophys Acta. 2009;1792(5):470-81. https://doi.org/10.1016/j.bbadis.2008.09.004.

35. Power MC, Rawlings A, Sharrett AR, Bandeen-Roche K, Coresh J, Ballantyne CM, et al. Association of midlife lipids with 20-year cognitive change: a cohort study. Alzheimers Dement. 2018;14(2):167-77. https:// doi.org/10.1016/j.jalz.2017.07.757.

36. Reitz C, Tang MX, Luchsinger J, Mayeux R. Relation of plasma lipids to Alzheimer disease and vascular dementia. Arch Neurol. 2004;61(5):705-14. https://doi.org/10.1001/archneur.61.5.705.

37. Pedditzi E, Peters R, Beckett N. The risk of overweight/obesity in mid-life and late life for the development of dementia: a systematic review and meta-analysis of longitudinal studies. Age Ageing. 2016;45(1):14-21. https ://doi.org/10.1093/ageing/afv151.

38. Fan YC, Hsu JL, Tung HY, Chou CC, Bai CH. Increased dementia risk predominantly in diabetes mellitus rather than in hypertension or hyperlipidemia: a population-based cohort study. Alzheimers Res Ther. 2017;9(1):7. https://doi.org/10.1186/s13195-017-0236-z.

39. Levin BE, Llabre MM, Dong C, Elkind MS, Stern Y, RundekT, et al. Modeling metabolic syndrome and its association with cognition: the Northern Manhattan study. J Int Neuropsychol Soc. 2014;20(10):951-60. https://doi. org/10.1017/S1355617714000861.

40. Jendroska K, Poewe W, Daniel SE, Pluess J, Iwerssen-Schmidt H, Paulsen $J$, et al. Ischemic stress induces deposition of amyloid beta immunoreactivity in human brain. Acta Neuropathol. 1995;90(5):461-6. https://doi. org/10.1007/BF00294806.

41. Riekse RG, Leverenz JB, McCormick W, Bowen JD, Teri L, Nochlin D, et al. Effect of vascular lesions on cognition in Alzheimer's disease: a community-based study. J Am Geriatr Soc. 2004;52(9):1442-8. https://doi. org/10.1111/j.1532-5415.2004.52405.X.

42. Gomez G, Beason-Held LL, Bilgel M, An Y, Wong DF, Studenski S, et al. Metabolic syndrome and amyloid accumulation in the aging brain. J Alzheimers Dis. 2018;65(2):629-39. https://doi.org/10.3233/JAD-180297.

43. Xue M, Xu W, Ou YN, Cao XP, Tan MS, Tan L, et al. Diabetes mellitus and risks of cognitive impairment and dementia: a systematic review and meta-analysis of 144 prospective studies. Ageing Res Rev. 2019;55:100944. https://doi.org/10.1016/j.arr.2019.100944.
44. Crane PK, Walker R, Hubbard RA, Li G, Nathan DM, Zheng H, et al. Glucose levels and risk of dementia. N Engl J Med. 2013;369(6):540-8. https://doi. org/10.1056/NEJMoa1215740.

45. Li X, Song D, Leng SX. Link between type 2 diabetes and Alzheimer's disease: from epidemiology to mechanism and treatment. Clin Interv Aging. 2015;10:549-60. https://doi.org/10.2147/CIA.S74042.

46. Tamura Y, Araki A. Diabetes mellitus and white matter hyperintensity. Geriatr Gerontol Int. 2015;15(Suppl 1):34-42. https://doi.org/10.1111/ ggi.12666.

47. Yang R, Pedersen NL, Bao C, Xu W, Xu H, Song R, et al. Type 2 diabetes in midlife and risk of cerebrovascular disease in late life: a prospective nested case-control study in a nationwide Swedish twin cohort. Diabetologia. 2019;62(8):1403-11. https://doi.org/10.1007/s00125-019-4892-3.

48. Arboix A, Rivas A, Garcia-Eroles L, de Marcos L, Massons J, Oliveres M. Cerebral infarction in diabetes: clinical pattern, stroke subtypes, and predictors of in-hospital mortality. BMC Neurol. 2005;5(1):9. https://doi. org/10.1186/1471-2377-5-9.

49. Moloney AM, Griffin RJ, Timmons S, O'Connor R, Ravid R, O'Neill C. Defects in IGF-1 receptor, insulin receptor and IRS-1/2 in Alzheimer's disease indicate possible resistance to IGF-1 and insulin signalling. Neurobiol Aging. 2010;31(2):224-43. https://doi.org/10.1016/j.neurobiolaging.2008.04.002.

50. Gerozissis K. Brain insulin, energy and glucose homeostasis; genes, environment and metabolic pathologies. Eur J Pharmacol. 2008;585(1):38-49. https://doi.org/10.1016/j.ejphar.2008.01.050.

51. Unger J, McNeill TH, Moxley RT, White M, Moss A, Livingston JN. Distribution of insulin receptor-like immunoreactivity in the rat forebrain. Neuroscience. 1989;31(1):143-57. https://doi.org/10.1016/0306-4522(89)90036 -5 .

52. Cipolla MJ, Liebeskind DS, Chan SL. The importance of comorbidities in ischemic stroke: impact of hypertension on the cerebral circulation. J Cereb Blood Flow Metab. 2018;38(12):2129-49. https://doi. org/10.1177/0271678X18800589.

53. Sacco RL, Benson RT, Kargman DE, Boden-Albala B, Tuck C, Lin IF, et al. High-density lipoprotein cholesterol and ischemic stroke in the elderly: the Northern Manhattan Stroke Study. JAMA. 2001;285(21):2729-35. https://doi.org/10.1001/jama.285.21.2729.

54. Suk SH, Sacco RL, Boden-Albala B, Cheun JF, Pittman JG, Elkind MS, et al. Abdominal obesity and risk of ischemic stroke: the Northern Manhattan Stroke Study. Stroke. 2003;34(7):1586-92. https://doi.org/10.1161/01. STR.0000075294.98582.2F.

55. Frisardi V, Solfrizzi V, Capurso C, Imbimbo BP, Vendemiale G, Seripa D, et al. Is insulin resistant brain state a central feature of the metabolic-cognitive syndrome? J Alzheimers Dis. 2010;21(1):57-63. https://doi.org/10.3233/ JAD-2010-100015.

56. Chi NF, Chien LN, Ku HL, Hu CJ, Chiou HY. Alzheimer disease and risk of stroke: a population-based cohort study. Neurology. 2013;80(8):705-11. https://doi.org/10.1212/WNL.0b013e31828250af.

57. Gamaldo A, Moghekar A, Kilada S, Resnick SM, Zonderman AB, O'Brien R. Effect of a clinical stroke on the risk of dementia in a prospective cohort. Neurology. 2006;67(8):1363-9. https://doi.org/10.1212/01.wnl.00002 40285.89067.3f.

58. Allan LM, Rowan EN, Firbank MJ, Thomas AJ, Parry SW, Polvikoski TM, et al. Long term incidence of dementia, predictors of mortality and pathological diagnosis in older stroke survivors. Brain. 2011;134(Pt 12):3716-27. https://doi.org/10.1093/brain/awr273.

59. Xing C, Arai K, Lo EH, Hommel M. Pathophysiologic cascades in ischemic stroke. Int J Stroke. 2012;7(5):378-85. https://doi.org/10.111 1/j.1747-4949.2012.00839.x

60. Vijayan M, Kumar S, Bhatti JS, Reddy PH. Molecular links and biomarkers of stroke, vascular dementia, and Alzheimer's disease. Prog Mol Biol Transl Sci. 2017;146:95-126. https://doi.org/10.1016/bs.pmbts.2016.12.014.

61. Snowdon DA. Brain infarction and the clinical expression of Alzheimer disease. The Nun Study. JAMA J Am Med Assoc. 1997;277:10. https://doi. org/10.1001/jama.1997.03540340047031.

62. Esiri MM, Nagy Z, Smith MZ, Barnetson L, Smith AD. Cerebrovascular disease and threshold for dementia in the early stages of Alzheimer's disease. Lancet. 1999;354(9182):919-20. https://doi.org/10.1016/s0140 -6736(99)02355-7.

63. Kalaria RN, Akinyemi R, Ihara M. Does vascular pathology contribute to Alzheimer changes? J Neurol Sci. 2012;322(1-2):141-7. https://doi. org/10.1016/j.jns.2012.07.032. 
64. Regan C, Katona C, Walker Z, Hooper J, Donovan J, Livingston G. Relationship of vascular risk to the progression of Alzheimer disease. Neurology. 2006;67(8):1357-62. https://doi.org/10.1212/01.wnl.0000240129.46080 53.

65. Pendlebury ST, Rothwell PM. Incidence and prevalence of dementia associated with transient ischaemic attack and stroke: analysis of the population-based Oxford Vascular Study. Lancet Neurol. 2019;18(3):24858. https://doi.org/10.1016/s1474-4422(18)30442-3.

66. Stevens J, Cai J, Pamuk ER, Williamson DF, Thun MJ, Wood JL. The effect of age on the association between body-mass index and mortality. N Engl J Med. 1998;338(1):1-7. https://doi.org/10.1056/NEJM199801013380101.

67. Rankinen T, Kim SY, Perusse L, Despres JP, Bouchard C. The prediction of abdominal visceral fat level from body composition and anthropometry: ROC analysis. Int J Obes Relat Metab Disord. 1999;23(8):801-9. https://doi. org/10.1038/sj.ijo.0800929.

68. Harvey J, Solovyova N, Irving A. Leptin and its role in hippocampal synaptic plasticity. Prog Lipid Res. 2006;45(5):369-78. https://doi.org/10.1016/j. plipres.2006.03.001.

69. Marseglia L, Manti S, D’Angelo G, Nicotera A, Parisi E, Di Rosa G, et al. Oxidative stress in obesity: a critical component in human diseases. Int J Mol Sci. 2014;16(1):378-400. https://doi.org/10.3390/ijms16010378.

70. Moh MC, Low S, Ng TP, Wang J, Ang SF, Tan C, et al. Association of traditional and novel measures of central obesity with cognitive performance in older multi-ethnic Asians with type 2 diabetes. Clin Obes. 2020;10(2):e12352. https://doi.org/10.1111/cob.12352.

71. Beydoun MA, Beydoun HA, Wang Y. Obesity and central obesity as risk factors for incident dementia and its subtypes: a systematic review and meta-analysis. Obes Rev. 2008;9(3):204-18. https://doi.org/10.1111/ j.1467-789X.2008.00473.x.

72. Tanner CM. Advances in environmental epidemiology. Mov Disord. 2010;25(Suppl 1):S58-62. https://doi.org/10.1002/mds.22721.

73. Fahn S. Parkinson's disease: 10 years of progress, 1997-2007. Mov Disord. 2010;25(Suppl 1):S2-14. https://doi.org/10.1002/mds.22796.

74. Nicoletti A, Pugliese P, Nicoletti G, Arabia G, Annesi G, Mari MD, et al. Voluptuary habits and clinical subtypes of Parkinson's disease: the FRAGAMP case-control study. Mov Disord. 2010;25(14):2387-94. https://doi. org/10.1002/mds.23297.

75. Picciotto MR, Zoli M. Neuroprotection via nAChRs: the role of nAChRs in neurodegenerative disorders such as Alzheimer's and Parkinson's disease. Front Biosci. 2008;13:492-504. https://doi.org/10.2741/2695.
76. Quik M, Perez XA, Bordia T. Nicotine as a potential neuroprotective agent for Parkinson's disease. Mov Disord. 2012;27(8):947-57. https://doi. org/10.1002/mds.25028.

77. Deckers K, van Boxtel MP, Schiepers OJ, de Vugt M, Munoz Sanchez JL, Anstey KJ, et al. Target risk factors for dementia prevention: a systematic review and Delphi consensus study on the evidence from observational studies. Int J Geriatr Psychiatry. 2015;30(3):234-46. https://doi. org/10.1002/gps.4245.

78. Collins N, Sachs-Ericsson N, Preacher KJ, Sheffield KM, Markides K. Smoking increases risk for cognitive decline among community-dwelling older Mexican Americans. Am J Geriatr Psychiatry. 2009;17(11):934-42. https:// doi.org/10.1097/JGP.0b013e3181b0f8df.

79. Rusanen M, Rovio S, Ngandu T, Nissinen A, Tuomilehto J, Soininen H, et al. Midlife smoking, apolipoprotein E and risk of dementia and Alzheimer's disease: a population-based cardiovascular risk factors, aging and dementia study. Dement Geriatr Cogn Disord. 2010;30(3):277-84. https:// doi.org/10.1159/000320484.

80. Calderon-Garciduenas L. Smoking and cerebral oxidative stress and air pollution: a dreadful equation with particulate matter involved and one more powerful reason not to smoke anything! J Alzheimers Dis. 2016;54(1):109-12. https://doi.org/10.3233/JAD-160510.

81. Gerzanich V, Zhang F, West GA, Simard JM. Chronic nicotine alters $\mathrm{NO}$ signaling of $\mathrm{Ca}(2+)$ channels in cerebral arterioles. Circ Res. 2001;88(3):359-65. https://doi.org/10.1161/01.res.88.3.359.

82. Wang P, Li B, Cai G, Huang M, Jiang L, Pu J, et al. Activation of PPARgamma by pioglitazone attenuates oxidative stress in aging rat cerebral arteries through upregulating UCP2. J Cardiovasc Pharmacol. 2014;64(6):497-506. https://doi.org/10.1097/FJC.0000000000000143.

83. Toda N, Okamura T. Cigarette smoking impairs nitric oxide-mediated cerebral blood flow increase: implications for Alzheimer's disease. J Pharmacol Sci. 2016;131(4):223-32. https://doi.org/10.1016/j.jphs.2016.07.001.

84. Durazzo TC, Mattsson N, Weiner MW. Alzheimer's Disease Neuroimaging I Smoking and increased Alzheimer's disease risk: a review of potential mechanisms. Alzheimers Dement. 2014;10(3 Suppl):S122-45. https://doi. org/10.1016/j.jalz.2014.04.009.

\section{Publisher's Note}

Springer Nature remains neutral with regard to jurisdictional claims in published maps and institutional affiliations.
Ready to submit your research? Choose BMC and benefit from:

- fast, convenient online submission

- thorough peer review by experienced researchers in your field

- rapid publication on acceptance

- support for research data, including large and complex data types

- gold Open Access which fosters wider collaboration and increased citations

- maximum visibility for your research: over $100 \mathrm{M}$ website views per year

At BMC, research is always in progress.

Learn more biomedcentral.com/submissions 